\title{
Body size and wing asymmetry in bees along an urbanization gradient
}

\author{
Weronika BanaszaK-CiBickA ${ }^{1}$, Monika FliszKIEwicz ${ }^{1}$, Aleksandra LANGOwsKA ${ }^{1}$, \\ Michał ŻMIHORSKI ${ }^{2,3}$
}

\footnotetext{
${ }^{1}$ Institute of Zoology, Poznań University of Life Sciences, Wojska Polskiego 71C, 60-625, Poznań, Poland ${ }^{2}$ Institute of Nature Conservation, Polish Academy of Sciences, al. A. Mickiewicza 33, 31-120, Kraków, Poland

${ }^{3}$ Department of Ecology, Swedish University of Agricultural Sciences, Box 7044, SE 750 07, Uppsala, Sweden
}

Received 11 May 2017 - Revised 8 October 2017 - Accepted 23 October 2017

\begin{abstract}
The global loss of bee diversity and abundance is a central issue in conservation biology. There is increasing evidence that cities may play an important role in bee conservation, although urbanization may also have negative impacts. Here, we investigate individual body size variation and wing asymmetry (based on 11 traits) in the solitary bee Anthophora plumipes along a rural-urban gradient in Poland. The body size of captured individuals did not show any changes along the gradient. Directional asymmetry was present, since differences between sides in 10 out of 11 traits deviated significantly from zero, with the right-side wing traits being generally larger. In contrast to our expectations, the forewing was more asymmetric in rural than in suburban and urban areas. Similarly, the absolute asymmetry of 11 wing traits (i.e. pooling differences but ignoring direction) was also significantly greater in rural than in suburban and urban landscapes. Since asymmetry may be attributed to environmental pollution and food shortages, we conclude that the urban landscape provides bees with habitats of higher quality and thus should be considered as an important habitat for bee conservation.
\end{abstract}

\section{hymenoptera / Apoidea / bees / city / directional asymmetry}

\section{INTRODUCTION}

The urbanization process is an important anthropogenic alteration of the modern landscape. There are over 800 cities in the EU with more than 50,000 inhabitants, and Europe annually lost over $1100 \mathrm{~km}^{2}$ of natural and semi-natural areas to urban or other artificial land (EEA 2016). Over $73 \%$ of the European human population is urbanized, and this figure is expected to reach $82 \%$ by

Electronic supplementary material The online version of this article (https://doi.org/10.1007/s13592-017-0554-y) contains supplementary material, which is available to authorized users.

Corresponding author: W. Banaszak-Cibicka, banaszak@up.poznan.pl

Manuscript editor: Stan Schneider
2050 (United Nations 2014). It is predicted that $77,500 \mathrm{~km}^{2}$ of the European landscape will have been converted to urban areas between 2000 and 2030 (EEA 2016).

As a consequence, urbanization is considered to be the main cause of species extinction and a threat to the highest number of species (Czech et al. 2000). We believe that, this process must have impacted bees as well. Urbanization is mainly associated with a decreasing coverage of natural vegetation, a high proportion of artificial surfaces (concrete, asphalt), air pollution, and an impoverished vegetation composed mainly of exotic plant species dominating in urban parks and gardens (Blair and Launer 1997; Williams et al. 2009). All of these changes appear negative for bees since they impede their breeding, foraging and may reduce survival of urban-living bees. One may assume, therefore, that 
urbanization causes a decline of bee diversity and contributes to overall bee reduction in the modern landscape (McIntyre and Hostetler 2001).

In contrast to these predictions, several studies show surprisingly high diversity of Apidae in cities (Zapparoli 1997; Cane 2005; Banaszak-Cibicka and Żmihorski 2012), and urban green areas are believed to be important bee reservoirs (Tommasi et al. 2004). On the other hand, high species richness or abundance confirmed in cities does not necessarily mean that bees are not being impacted by urbanization. This impact can alter species composition, and change the biology or behaviour of citydwelling individuals, while leaving overall abundance constant. Urban bees living in a completely new habitat face different challenges compared to those from natural habitats. Thus, different species traits determining survival in urbanized areas can be favoured by natural selection (Chapman et al. 2003; Slabbekoorn and Peet 2003). Furthermore, since urban habitats provide bees with different resources (e.g., exotic plants) and threats (pollution), the biology and ecology of urban bees are probably adapted to these conditions. Thus, to understand the impact of urbanization on bees other elements of their ecology and biology also need to be examined. Unfortunately, the urbanization impact on bees has not been explored extensively (McIntyre 2000; Cane and Tepedino 2001) since most of the existing studies focused largely on taxonomic composition and abundance (Zapparoli 1997; Tommasi et al. 2004; Ahrné et al. 2009), thus leaving open the question of the consequences of urbanization on the ecology of bees.

Our previous research has demonstrated that interspecific differences in body size determine the colonization of an urban environment by bees: large-bodied species were more numerous in the suburbs while small species dominated in the city centre (Banaszak-Cibicka and Żmihorski 2012). The occurrence of small bee species in city centres may be related to a smaller amount of available food, thus urban areas may act as environmental filters (Tscharntke et al. 2012) which has been observed for beetles and spiders (Weller and Ganzhorn 2004). To the best of our knowledge, there have been no studies investigating the impact of urbanization on the size of bees within one species (i.e. individual variation).
In bees, body size is partly affected by food resources available (Bosch and Vicens 2002). Simultaneously, body size of imagines determines the amounts of pollen a bee may collect and is important when it comes to the sex ratio of their offspring, since smaller individuals may produce more sons (Seidelmann et al. 2010). There is also a positive correlation between body size and flight distances (Araújo et al. 2004). Individual variation in body size may therefore be an important adaptation of bees to urban habitats.

The pattern of symmetry of body bilateral structures can also be used as an indicator of environmental conditions (Møller and Swaddle 1997) and thus can potentially reflect an urbanization effect. Random deviation from bilateral symmetry, sometimes called 'fluctuating asymmetry' (FA) (Polak and Triners 1994), reflects developmental stability and is considered an indicator of environmentally induced stress in organisms (Palmer and Strobeck 1992). FA is a measure of the genome's ability to successfully buffer development to achieve a normal phenotype under stressful environmental conditions (Waddington 1942). This is why the genetic background of an individual, population structure and levels of inbreeding may also play roles in susceptibility to stress-induced asymmetry. An elevated level of asymmetry may correlate with the fitness of an individual (Møller 1997) and commonly occurring stressors that increase asymmetry include air and water pollution, pesticides, temperature, food deficiency and parasitism (De Anna et al. 2013). Directional asymmetry is another form of bilateral asymmetry which differs from fluctuating asymmetry in that one side is consistently larger than the other (Van Valen 1962) and may also be a potential indicator of developmental stability (Graham et al. 1993, 1998). It is, therefore, likely that the level of body asymmetry in bees can be shaped by urbanization, although to the best of our knowledge, this issue has not been investigated in wild bees so far.

The potential differences in environmental quality between urban and rural habitats may affect not only the loss of bee diversity but also the quality of bees. In this study, we investigate body size and wing asymmetry (as a measure of bee quality) within one solitary-living wild bee 
species, Anthophora plumipes, in rural, suburban and urban landscapes. Following our previous findings that smaller bodied species preferred the city centre (Banaszak-Cibicka and Żmihorski 2012) we hypothesize that smaller individuals within the species will occur in the city centre compared to rural areas. Secondly, we expect higher body asymmetry in bees in urbanized landscapes compared to suburban and rural landscapes, reflecting unfavourable urban conditions.

\section{MATERIALS AND METHODS}

\subsection{Study area}

The study was carried out in 2014 in Poznań $\left(52^{\circ} 25^{\prime} \mathrm{N}, 16^{\circ} 58^{\prime} \mathrm{E}\right)$, Poland, a city with 560,000 residents, and its surroundings. Study plots were selected on a gradient of urbanization and represented urban, suburban and rural areas.

Seventeen 4-ha plots (rural 6, suburban 5, urban 6 ), were chosen along the gradient. Rural plots were located mainly in villages or arable fields with the surroundings dominated by arable fields, grasslands and small woodlots. Suburban plots were placed in city districts dominated by detached houses and large urban green areas. Urban plots were located in small urban parks or scattered in urban greenery along streets, in the city centre. The ground cover of artificial structures (buildings and streets) was calculated for each plot based on satellite images and differed clearly between the three landscapes (mean coverage: rural 3\%, suburban $20 \%$ and urban 55\%). During fieldwork, the most abundant flowering plant species visited by Anthophora plumipes in all plots, was Lamium purpureum L. A. plumipes almost exclusively visited the flowers of this plant, along with L. album L., however, the latter plant species was not present in all plots. In the rural landscape, the majority of A. plumipes was observed at L. album, which was more abundant than L. purpureum in most rural plots. The main co-flowering and insect-pollinated plant was Taraxacum officinale F. H. Wigg., but its flowers were visited only sporadically by A. plumipes. In urban and suburban landscapes some bees were also observed at Chaenomeles japonica (Thunb.) Lindl. ex Spach. which was apparently more attractive to the bee than
Taraxacum. C. japonica was the only species among many other co-flowering Rosaceae plants that was visited by $A$. plumipes. Bees were also attracted to Pulmonaria obscura Dumort and Glechoma hederacea L., plants common in some rural plots, and some individuals of $A$. plumipes were spotted at Salix spp.

\subsection{Study organism}

Anthophora is a large genus of fast-flying, robust bees occurring on all continents except Australia and South America. In Poland, the commonest species is Anthophora plumipes (Pallas, 1772). A. plumipes flies from March until May. Choosing a solitary species for the study eliminates the problem of morphological variability between reproductive and non-reproductive females in social species, that could bias results. Moreover, A. plumipes builds nests underground. Therefore, the size and shape of nest cells where the larvae develop are not predetermined as, in the case of bees nesting in various structures, such as grass stems or wood, where the body size of the larva is adjusted to the nesting location.

\subsection{Bee capturing}

On all plots, individual specimens were captured by hand with an insect net during the flying period of the species, i.e. March-May, however in March, only male bees were active. Bees were sampled on each plot for an hour between 10 a.m. and 3 p.m. during warm and sunny weather. Each plot was visited three times and all plots were surveyed at least once in the morning and at least once in the afternoon. The collected insects were put in ethyl acetate and then transported to a laboratory where their species identity was confirmed. On average, nine individuals were captured on each plot (mean, rural 9; suburban 7, urban 10). A total of 153 bees were caught and measured.

\subsection{Body length and wing measurements}

Pictures of wings and thorax of the captured insects were taken under a stereoscopic microscope (Stereo Lumar v. 12 by Zeiss) and saved in a format compatible with software devoted to 
image analysis (AxioVision rel. 4.6. by Zeiss). All the measurements were performed with the use of this software.

Body mass may vary a lot due to differences in the amount of food (and waste) filling the intestines (Cane 1987). Therefore, the distance between the tegulae (intertegular distance) was used as a proxy of body size (Cane 1987). We selected 11 distances between characteristic points of the wing structure (wing vein lengths and wing cell lengths - measured in a straight line) on forewings and hindwings (Figure 1). Such wing morphometrics have been successfully used to estimate asymmetry (Tsubaki 1998; Schmeller et al. 2011). Each wing and intertegular distance was measured twice, and these measurements were independent and were used to assess measurement error.

\subsection{Asymmetry}

First, the difference between the measurements of the left and right side of each trait was calculated and termed "asymmetry" (i.e. left - right = asymmetry). Asymmetry is either negative (right-side wing larger) or positive (left-side wing larger) and asymmetry equal to zero means perfect symmetry (i.e. no differences between sides). In total, 1617 asymmetry calculations were done (153 individuals $\times 11$ traits $=1683$, except for 66 cases for which measurements of both sides were not available).

Second, we calculated mean asymmetry for all seven traits measured on the forewing and four traits measured on the hindwing. To do this, we first rescaled variation in asymmetry of each of the eleven traits, such that range of rescaled traits equalled 100. Zero indicated no asymmetry, while negative and positive values indicated right or left size larger, respectively. Each of the rescaled traits, however, had different minimum and maximum values, although the range was always 100 . After this, each trait had the same weight in further averaging despite differences in the original values. Next, we calculated the mean of all eleven rescaled values (hereafter termed mean asymmetry) available for each individual (in 48 individuals not all 11 traits were measured on both sides). The mean asymmetry of a given wing takes all the traits on that wing into account and shows whether right or left wing is generally larger.

Third, we calculated absolute asymmetry, by taking absolute values (i.e. modulus) of the difference between the left and right side (1617 absolute asymmetry calculations). The absolute values thus indicate the difference between the larger and smaller side. Next, we rescaled the variation in absolute asymmetry of each of the 11 traits to be from 0 to 100 to ensure equal weights of the different traits, and calculated the mean absolute asymmetry for forewings and hindwings.

As a result, we had four types of asymmetry estimations: mean asymmetry and mean absolute asymmetry of the forewing and the hindwing. These four asymmetry estimations were used as response variables in further statistical analyses.

\subsection{Anomalies}

Apart from measurements, all the wings were inspected for any anomalies in a general picture of their venation.

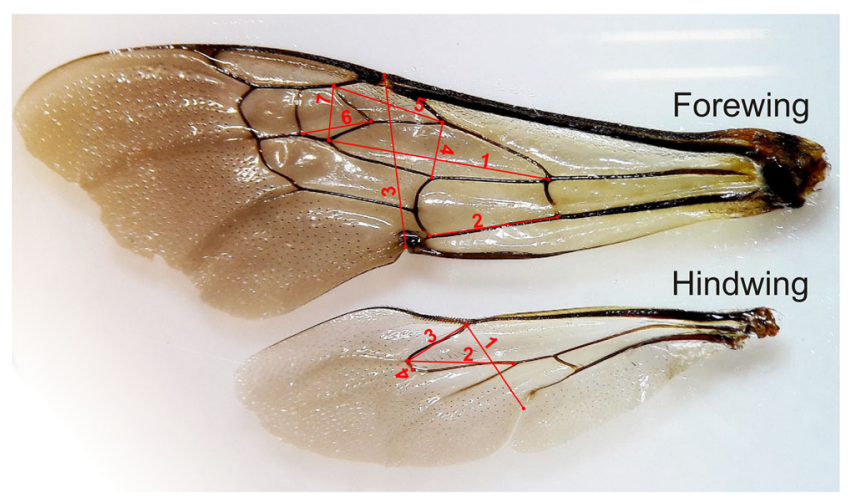

Figure 1. Eleven forewing (FW1-7) and hindwing (HW1-4) traits measured in 153 bees. 


\subsection{Statistical analysis}

First, we estimated repeatability of the measurements taken. For this purpose, we correlated first and second measurements for each trait and side independently ( 11 traits $\times 2$ sides $=22$ correlations in total). Next, pairwise correlations between traits were calculated in order to test association among traits. Furthermore, we tested fluctuating vs. directional asymmetry for all the 11 traits independently with the help of intercept-only linear models: significance of the intercept indicates mean asymmetry not overlapping zero (i.e. directional asymmetry) while a non-significant intercept indicates fluctuating asymmetry.

We performed general linear mixed models (GLMM) with a Gaussian error distribution to compare body length and wing asymmetry of the studied bees. First, we performed a model (GLMM 1) examining body length of bees among the three habitats. In this model, habitat type was included an explanatory variable and site ID was introduced as a random effect. Next, we performed four models explaining asymmetry: mean asymmetry of the forewing (GLMM 2.1), mean asymmetry of the hindwing (GLMM 2.2), mean absolute asymmetry of the forewing (GLMM 3.1) and mean absolute asymmetry of the hindwing (GLMM 3.2). In these four models, body length and habitat type were included as explanatory variables while site ID was a random effect.

As supplementary analyses, we also performed separate GLMMs on each trait independently (11 models for asymmetry and 11 for absolute asymmetry) to investigate trait-specific variation among habitats and these results are presented as supplementary material. All the models were performed in the 'nlme' package (Pinheiro et al. 2016) in R (R Core Team 2016).

\section{RESULTS}

\subsection{Repeatability of the wing measurements}

In all of the traits, we recorded a high repeatability of the measurements (correlation between first and second measurement $>0.9$ in all cases, Online Resource-Fig. S1).

\subsection{Correlations among measurements}

Measurements were positively correlated among traits but mainly within wing, rarely between wings. All significant correlations were positive, but not very strong $(r<0.5$ in all cases; Online Resource_Fig. S1).

\subsection{Directional asymmetry}

Ten out of eleven traits significantly deviated from symmetry, i.e. the average difference between left and right sides was significantly different from zero, thus indicating directional asymmetry. In eight cases, measurements taken on the right side were significantly larger than measurements taken on the left side; while for two traits, the opposite pattern was recorded (Figure 2).

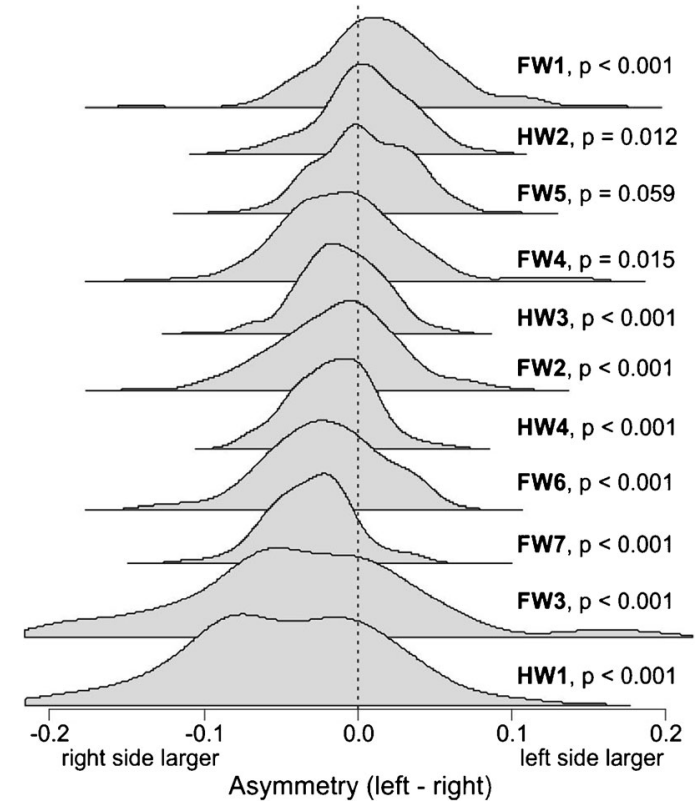

Figure 2. Distribution of the asymmetry (difference between left and right sides, visualised with kernel density) of 11 forewing (FW1-7) and hindwing (HW1-4) traits in 153 bees, accompanied by $p$ values based on intercept-only linear models. Vertical dashed line indicates zero (perfect symmetry). See Fig. 1 for visualization of wing measurements. 


\subsection{Urbanization effect}

The body size of bees did not show differences among the three studied habitats (GLMM 1, Table I). Overall mean asymmetry of the forewing was negative (Figure 3) indicating larger right side traits, but was less negative in suburban and urban habitats compared to rural (GLMM 2.1). No such differences were observed for the hindwing (GLMM 2.2). Mean absolute asymmetry of the forewing was lower in suburban and urban habitats compared to the rural habitat (GLMM 3.1), and a similar pattern was recorded for the hindwing (GLMM 3.2, although no difference between rural and suburban habitats was recorded). Thus urban bees were less asymmetric compared to bees found in rural areas.

\subsection{Anomalies}

Apart from measuring differences in veins length, the wings were inspected for other anomalies. Apparent changes in a vein picture were observed in only one suburban individual; its second submarginal cross-vein $(1 \mathrm{r}-\mathrm{m})$ was reduced on both wings and first submarginal cross-vein $\left(\mathrm{RS}^{1}\right)$ was missing in the left wing.

\section{DISCUSSION}

Our investigations confirm that body size of the studied bee species did not differ among the three types of habitats considered: rural, suburban and urban. Therefore, our predictions concerning urbanization-body size relationships were not confirmed. We did, however, find that both rural and urban-dwelling bees were significantly

Table I. Summary of general linear mixed models explaining body size, average asymmetry and average absolute asymmetry (see methods for definitions) in 153 bees in rural, suburban and urban habitats. Rural habitat is a reference category (b parameter for this level is zero), significant and marginally significant $(p<0.1)$ effects are marked in bold.

\begin{tabular}{lllcrr}
\hline Model & Response & Predictor & $\mathrm{b}$ (SE) & $t$ value & $p$ value \\
\hline GLMM 1 & Body size & Intercept & $3.86(0.03)$ & 149.25 & $<\mathbf{0 . 0 0 0 1}$ \\
& & Habitat: suburban & $-0.02(0.04)$ & 0.60 & 0.5622 \\
GLMM 2.1 & Mean asymmetry of & Habitat: urban & $0.03(0.03)$ & 1.01 & 0.3342 \\
& forewing & Intercept & $44.81(18.24)$ & 2.46 & $\mathbf{0 . 0 1 5 8}$ \\
& & Habitat: suburban & $6.16(1.83)$ & 3.37 & $\mathbf{0 . 0 0 6 3}$ \\
& & Habitat: urban & $3.79(1.55)$ & 2.45 & $\mathbf{0 . 0 3 2 3}$ \\
GLMM 2.2 & Mean asymmetry of & Body size & $0.40(4.73)$ & 0.08 & 0.9332 \\
& hindwing & Intercept & $62.57(27.83)$ & 2.25 & $\mathbf{0 . 0 2 6 2}$ \\
& & Habitat: suburban & $1.55(2.79)$ & 0.56 & 0.5894 \\
& & Habitat: urban & $2.71(2.33)$ & 1.16 & 0.2691 \\
GLMM 3.1 & Mean absolute & Body size & $-2.94(7.20)$ & 0.41 & 0.6834 \\
& asymmetry of forewing & Intercept & $42.84(19.18)$ & 2.23 & $\mathbf{0 . 0 2 7 2}$ \\
& & Habitat: suburban & $-4.42(1.92)$ & 2.30 & $\mathbf{0 . 0 4 2 2}$ \\
& & Habitat: urban & $-5.23(1.63)$ & 3.22 & $\mathbf{0 . 0 0 8 2}$ \\
& & Body size & $-3.76(4.97)$ & 0.76 & 0.4503 \\
GLMM 3.2 & Mean absolute & Intercept & $-20.77(27.69)$ & 0.75 & 0.4546 \\
& asymmetry of hindwing & Habitat: suburban & $-1.77(2.78)$ & 0.64 & 0.5369 \\
& & Habitat: urban & $-6.04(2.32)$ & 2.60 & $\mathbf{0 . 0 2 4 5}$ \\
& & Body size & $12.98(7.17)$ & 1.81 & $\mathbf{0 . 0 7 2 3}$ \\
\hline & & & & &
\end{tabular}


Asymmetry: left - right side [mm]

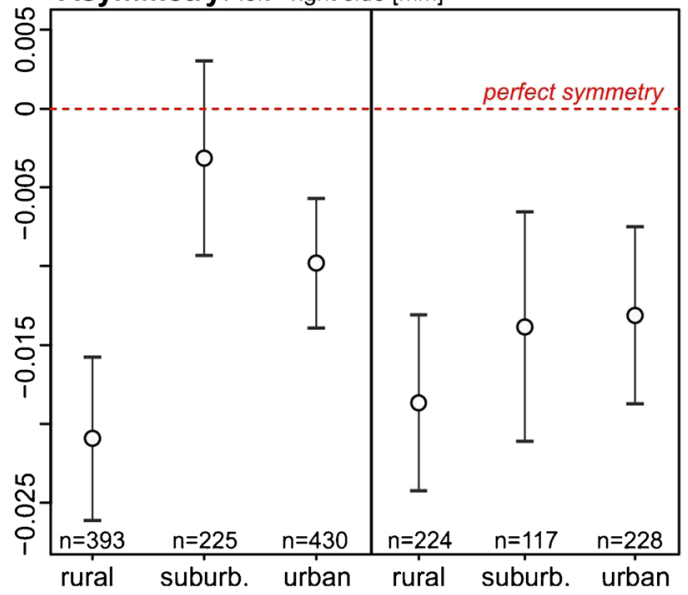

Absolute asymmetry: modulus (left - right side) [mm]

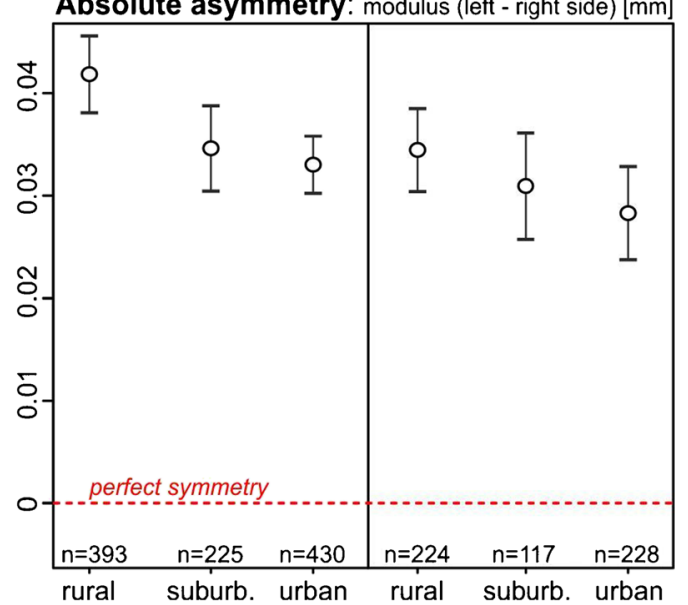

Figure 3. Asymmetry (top subplots) and absolute asymmetry (bottom subplots) of forewings and hindwings of bees living in rural, suburban and urban habitats.

asymmetric and the asymmetry was only directional (not fluctuating, as expected) since the right-side wing traits were significantly larger. Furthermore, we showed that urban bees were less asymmetric compared to bees collected in the rural landscape. Below, we discuss possible drivers of these results.

Within-species body size variation is a morphological measure which may indicate environmental quality. Distinct body size patterns have been reported for beetle assemblages influenced by the disturbance level of an area. Within species, the body length of Carabus nemoralis declined significantly towards the city centre (Weller and Ganzhorn 2004). On the other hand, individuals of Pterostichus madidus and Abax parallelepipedus were found to be larger in more urban sites (Sadler et al. 2006). Changes in body size distributions across an environmental gradient may reflect differences in resource availability or stress. Pollen limitation affects the body mass of bees (Szentgyörgyi et al. 2016), and in turn, the body mass of individuals affects female fecundity, especially in solitary bees (Sugiura and Maeta 1989; Kim 1997). Large individuals can transport large amounts of pollen (food for larvae) and complete more brood cells per time unit than small individuals (Strohm and Linsenmair 1997). Due to a large amount of food, offspring of these bees will also become large (Stone 1994; Bosch and Vicens 2002). In our study, however, we did not observe differences in the body size of bees collected in different landscapes. We may conclude, therefore, that the amount of food was stable throughout the urban-rural gradient in Poznań. The captured specimens of Anthophora plumipes foraged mainly on Lamium purpureum which grows in different habitats. Although the plant is considered as a weed it was abundant on all studied plots, including urban.

Animals have bilaterally symmetrical construction of the body plan. Nonetheless they can also display different types of asymmetry: fluctuating asymmetry, directional asymmetry and antisymmetry. Asymmetry increases with declines in environmental quality and correlates with fitness of an individual (Thornhill 1991; Møller 1994). Asymmetrical individuals have lower mating success and fecundity, and asymmetry may also have direct effects on survival (Møller 1997; Ondo et al. 2011). Directional asymmetry, demonstrated in bee wings in our study, occurs throughout the animal kingdom (Palmer 1996) and is widely recorded in the wing size of insects (Pélabon and Hansen 2008), including honey bees (Smith et al. 1997; Schneider et al. 2003). In Apis mellifera, the right wings were shown to be larger than the left wings (Szentgyörgyi et al. 2016) similar to the wings of Anthophora plumipes in our research. Directional asymmetry probably has a genetic basis (Palmer 
and Strobeck 1992) but environmental conditions may also contribute to it (Graham et al. 1993; Henshel et al. 1993; Lens and van Dongen 2000). Therefore it is possible to generate directional asymmetry by stressing an organism (Graham et al. 1993; Hoffmann and Merilä 1999; Lens and Van Dongen 2000) even over a very short time period (Pélabon et al. 2006).

In our study, directional asymmetry clearly differed among the habitats studied. Surprisingly, urban bees were less asymmetric compared to bees in rural areas. Previous studies have shown that there is a great diversity of wild bees within urban areas, including rare species (Zapparoli 1997; BanaszakCibicka 2014). This may suggest that habitat quality in the city is, at least, not worse than rural landscapes. Cities are characterised by urbanspecific abiotic conditions, such as the "urban heat island" with higher mean temperatures, earlier springs and longer frost-free seasons (Mitchell et al. 2002) which can positively affect bees. The urban microclimate has the potential to provide developmental stability for bee larvae because of the more stable temperatures to which organisms are exposed. Secondly, it is not obvious that environmental pollution increases with urbanization, since in farmland a great amount of insecticides is being applied, while cities seem to be pesticide-free zones. Urban habitats may also provide rich food resources and foraging opportunities for bees, thus increasing bee abundance and density (Blackmore and Goulson 2014; Banaszak-Cibicka et al. 2016).

Several former studies have shown the presence of a large number of bee species and individuals in the cities. Our results, however, indicate that cities may offer favourable conditions not only for bee species diversity, but also at the individual level. It seems that bees can find appropriate food sources and nesting places despite habitat alteration and thus can overcome the negative effects of urbanization pressure and develop sustainable urban populations (Westrich 1996). Hence, urban areas may play an important role in bee conservation (Zapparoli 1997). However, considering the abundance of wild flora available for bees in our study throughout the urbanization gradient, we suggest that planning and managing (e.g., mowing intensity) of urban greenery should be adjusted to the habitat requirements of bees.

\section{ACKNOWLEDGEMENTS}

The contribution by W.B.C., M.F., and A.L. was funded by a grant for young researchers from Poznan University of Life Sciences to W.B.C.

\section{AUTHOR CONTRIBUTIONS}

Conceived and designed the experiments: WBC. Performed the experiments: WBC, MF and AL. Statistical expertize: MŻ. Data analysis and interpretation: WBC and MŻ. Wrote the paper: WBC, MŻ and AL. All authors read and approved the final manuscript.

\section{COMPLIANCE WITH ETHICAL STANDARDS}

Conflict of interest The authors declare that they have no conflict of interest.

\section{OPEN ACCESS}

This article is distributed under the terms of the Creative Commons Attribution 4.0 International License (http://creativecommons.org/licenses/by/4.0/), which permits unrestricted use, distribution, and reproduction in any medium, provided you give appropriate credit to the original author(s) and the source, provide a link to the Creative Commons license, and indicate if changes were made.

Taille du corps et asymétrie des ailes chez des abeilles le long d'un gradient d'urbanisation

Hymenoptera / Apoidea / zone urbaine / asymétrie directionnelle / Anthophora plumipes

Körpergröße und Flügel-Asymmetrie von Bienen entlang eines urbanen Gradienten

Hymenoptera / Apoidea / Bienen / Stadt / direktionale Asymmetrie / Anthophora plumipes

\section{REFERENCES}

Ahrné K, Bengtsson J, Elmqvist T (2009) Bumble Bees (Bombus spp) along a Gradient of Increasing Urbanization. PLoS ONE 4: e5574 
Araújo ED, Costa M, Chaud-Netto J, Fowler HG (2004) Body size and flight distance in stingless bees (Hymenoptera: Meliponini): inference of flight range and possible ecological implications. Braz. J. Biol. 64: 563-568

Banaszak-Cibicka W (2014) Are urban areas suitable for thermophilic and xerothermic bee species (Hymenoptera: Apoidea: Apiformes)? Apidologie 45: 145-155

Banaszak-Cibicka W, Żmihorski M (2012) Wild bees along an urban gradient: winners \& losers. J. Insect Conserv. 16: $331-343$

Banaszak-Cibicka W, Ratyńska H, Dylewski Ł (2016) Features of urban green space favourable for large and diverse bee populations (Hymenoptera: Apoidea: Apiformes). Urban For \& Urban Green 20: 448-452

Blackmore LM, Goulson D (2014) Evaluating the effectiveness of wildflower seed mixes for boosting floral diversity and bumblebee and hoverfly abundance in urban areas. Insect Conserv. Divers. 7: 480-484

Blair RB, Launer AE (1997) Butterfly diversity and human land use: species assemblages along an urban gradient. Biol. Conserv. 80: 113-125

Bosch J, Vicens N (2002) Body size as an estimator of production costs in a solitary bee. Ecol. Entomol. 27: 129-137

Cane JH (1987) Estimation of bee size using intertegular span (Apoidea). J. Kansas Entomol. Soc. 60: 145-147

Cane JH (2005) Bees, pollination, and the challenges of sprawl. In: Johnson EA, Klemens MW (eds), Nature in fragments: the legacy of sprawl. Columbia University Press, New York pp 109-124.

Cane JH, Tepedino VJ (2001) Causes and extend of declines among native North American invertebrate pollinators: detection, evidence, and consequences. Conserv. Ecol. 5: 1

Chapman RE, Wang J, Bourke AFG (2003) Genetic analysis of spatial foraging patterns and resource sharing in bumble bee pollinators. Mol. Ecol. 12: 2801-2808

Czech B, Krausmann PR, Devers PK (2000) Economic association among causes of species endangerment in the United States. Bioscience 50: 593-601

De Anna EB, Bonisoli-Alquati A, Mousseau TA (2013) The use of fluctuating asymmetry as a measure of environmentally induced developmental instability: A meta-analysis. Ecol. Indic. 30: 218-226

EEA (2016) Urban sprawl in Europe. European Environment Agency, Report 11/2016, pp. 140

Graham JH, Roe KE, West TB (1993) Effects of lead and benzene on the developmental stability of Drosophila melanogaster. Ecotoxicology 2: 185-195

Graham JH, Emlen JM, Freeman DC, Leamy LJ, Kieser JA (1998) Directional asymmetry and the measurement of developmental instability. Biol. J. Linn. Soc. 64: 1-16

Henshel DS, Cheng KM, Norstrom R, Whitehead P, Steeves JD (1993) Morphometric and histologic changes in brains of great blue heron hatchlings exposed to PCDDs: preliminary analyses. In: Landis
WG, Hughes JS, Lewis MA (eds) Environmental Toxicology and Risk Assessment. Philadelphia: American Society for Testing and Materials, 262-277

Hoffmann AA, Merilä J (1999) Heritable variation and evolution under favourable and unfavourable conditions. Trends Ecol. Evol. 14: 96-101

Kim JY (1997) Female size and fitness in the leaf-cutter bee Megachile apicalis . Ecol. Entomol. 22: 275-282

Lens L, Van Dongen S (2000) Fluctuating and directional asymmetry in natural bird populations exposed to different levels of habitat disturbance, as revealed by mixture analysis. Ecol. Lett. 3: 516-522

McIntyre NE (2000) Ecology of urban arthropods: a review and a call to action. Ann. Entomol. Soc. Am. 93: 826835

McIntyre ME, Hostetler NE (2001) Effects of urban land use on pollinator (Hymenoptera: Apoidea) communities in a desert metropolis. Basic Appl. Ecol. 2: 209218

Mitchell TD, Hulme M, New M (2002) Climate data for political areas. Area 34: 109-112.

Møller AP (1994) Sexual selection in the barn swallow (Hirundo rustica). IV. Patterns of fluctuating asymmetry and selection against asymmetry. Evolution 48: 658-670.

Møller AP (1997) Developmental stability and fitness: a review. Am. Nat. 149: 916-932

Møller AP, Swaddle JP (1997) Asymmetry, developmental stability and evolution. Oxford University Press, UK

Ondo ZAN, Alibert P, Dousset S, Savadogo PW, Savadogo M, Sedogo M (2011) Insecticide residues in cotton soils of Burkina Faso and effects of insecticides on fluctuating asymmetry in honey bees (Apis mellifera Linnaeus). Chemosphere 83: 585-592

Palmer AR (1996) From symmetry to asymmetry: phylogenetic patterns of asymmetry variation in animals and their evolutionary significance. Proc. Natl. Acad. Sci. 93: 14279-14286

Palmer AR, Strobeck C (1992) Fluctuating asymmetry as a measure of developmental stability: implications of non-normal distributions and power of statistical tests. Acta Zool. Fenn. 191: 57-72

Pélabon C, Hansen TF (2008) On the adaptive accuracy of directional asymmetry in insect wing size. Evolution 62: 2855-2867

Pélabon C, Hansen TF, Carter AJR, Houle D (2006) Response of fluctuating and directional asymmetry to selection on wing shape in Drosophila melanogaster. J. Evol. Biol. 19: 764-776

Pinheiro J, Bates D, DebRoy S, Sarkar D, R Core Team (2016) nlme: linear and nonlinear mixed effects models. R package version 3.1-128. URL: http:/CRAN.R-project.org/package $=$ nlme

Polak M, Triners R (1994) The science of symmetry in biology. Trends Ecol. Evol. 9: 122-124

R Core Team (2016) R: A language and environment for statistical computing. R Foundation for Statistical Computing, Vienna. https://www.R-project.org/ 
Sadler JP, Small EC, Fiszpan H, Telfer MG, Niemelä J (2006) Investigating environmental variation and landscape characteristics of an urban-rural gradient using woodland carabid assemblages. J. Biogeogr. 33: 11261138

Schmeller DS, Dolek M, Geyer A, Settele J, Brandl R (2011) The effect of conservation efforts on morphological asymmetry in a butterfly population. J. Nat. Conserv. 19: 161-165

Schneider SS, Leamy LJ, Lewis LA, DeGrandi-Hoffman G (2003) The influence of hybridization between African and European honeybees, Apis mellifera, on asymmetries in wing size and shape. Evolution 57: 2350-2364

Seidelmann K, Ulbrich K, Mielenz N (2010) Conditional sex allocation in the Red Mason bee, Osmia rufa. Behav. Ecol. Sociobiol. 64: 337-347

Slabbekoorn H, Peet M (2003) Birds sing at a higher pitch in urban noise - great tits hit the high notes to ensure that their mating calls are heard above the city's din. Nature 424: 267-267

Smith DR, Crespi BJ, Bookstein FL (1997) Fluctuating asymmetry in the honey bee, Apis mellifera: effects of ploidy and hybridization. J. Evol. Biol. 10: $551-574$

Stone GN (1994) Activity patterns of females of the solitary bee Anthophora plumipes in relation to temperature, nectar supplies and body size. Ecol. Entomol. 19: 177-189

Strohm E., Linsenmair KE (1997) Female size affects provisioning and sex allocation in a digger wasp. Anim. Behav. 54: 23-34

Sugiura N, Maeta Y (1989) Parental investment and offspring sex ratio in a solitary mason bee, Osmia cornifrons (Radoszkowski) (Hymenoptera, Megachilidae). Jpn. J. Entomol. 57: 861-875

Szentgyörgyi H, Czekońska K, Tofilski A (2016) Influence of pollen deprivation on the fore wing asymmetry of honeybee workers and drones. Apidologie 47: 653-662
Thornhill R (1991) Female preference for the pheromone of males with low fluctuating asymmetry in the Japanese scorpionfly (Panorpa japonica: Mecoptera). Behav. Ecol. 3: 277-283

Tommasi D, Miro A, Higo HA, Winston ML (2004) Bee diversity and abundance in an urban setting. Can. Entomol. 136: 851-869

Tscharntke T, Tylianakis JM, Rand TA, Didham RK, Fahrig L, et al. (2012) Landscape moderation of biodiversity patterns and processes - eight hypotheses. Biol. Rev. 87: 661-685

Tsubaki Y (1998) Fluctuating asymmetry of the Oriental fruit fly (Dacus dorsalis) during the process of its extinction from the Okinawa Islands. Conserv. Biol. 12: 926-929

United Nations (2014) World population prospects: The 2010 revision and world urbanization prospects: The 2011 revision. Retrieved 24.02.2014, from http://esa. un.org/unup/unup/index _panel1.html

Van Valen L (1962) A study of fluctuating asymmetry. Evolution 16: 125-142

Waddington CH (1942) Canalization of development and the inheritance of acquired characters. Nature 150: 563-565

Weller B, Ganzhorn JU (2004) Carabid beetle community composition, body size, and fluctuating asymmetry along an urban-rural gradient. Basic Appl. Ecol. 5: 193-201

Westrich P (1996) Habitat requirements of central European bees and the problems of partial habitats. In: Matheson A, Buchmann S, O'Toole C, Westrich P, Williams IH (eds), The Conservation of Bees. Academic Press, London, pp 2-16

Williams NS, Schwartz MW, Vesk PA, McCarthy MA, Hahs AK, Clemants SE, Corlet RT, Duncan RP, Norton BA, Thompson K, McDonnell MJ (2009) A conceptual framework for predicting the effects of urban environments on floras. J. Ecol. 97: 4-9

Zapparoli M (1997) Urban development and insect biodiversity of the Rome area, Italy. Landsc. Urban Plan. 38: $77-86$ 